\title{
Characterization and Disintegrant Potential of Phosphorylated Tiger Nut (Cyperus esculentus) Starch in Immediate Release Ibuprofen Tablet Formulation
}

\author{
Onyinye D. Onwuatuegwu, Chukwuemeka P. Azubuike, Sinmisola Aloko, \\ Modupe 0. Ologunagba and Cecilia I. Igwilo
}

\author{
Department of Pharmaceutics and Pharmaceutical Technology, Faculty of Pharmacy, University of Lagos \\ College of Medicine Campus, PMB 12003, Surulere, Lagos, Nigeria
}

(Received: July 02, 2018; Accepted: December 26, 2018; Published (Web): April 01, 2019)

\begin{abstract}
The study was aimed at evaluating the physicochemical properties of phosphorylated tiger nut starch (TNP) and its disintegrant properties in immediate release ibuprofen tablets. Native tiger nut starch (TNS) was modified by phosphorylation with disodium hydrogen orthophosphate at $130^{\circ} \mathrm{C}$ and its physicochemical properties were evaluated. Ibuprofen tablets were formulated with TNP and sodium starch glycolate (SSG) at concentrations of 5.0, 7.5, 10.0 and $15.0 \%$ as disintegrants. Phosphorylation of TNS led to improved flow properties and swelling and hydration capacities among other changes in the physicochemical properties. TNP had comparable properties with SSG. FTIR study confirmed modification and also showed that TNP is compatible with ibuprofen powder. Ibuprofen tablets produced with TNP as disintegrant had acceptable tablet properties comparable to those produced with SSG. The disintegrant potential improved with increased concentration of TNP. The results indicate that TNP has a promising disintegrant potential in tablet formulations.
\end{abstract}

Key words: Cyperus esculentus starch, phosphorylation, modifiedstarch, disintegrant, ibuprofen tablet.

\section{INTRODUCTION}

There is a growing interest in continued explorations of novel pharmaceutical excipients with unique physicochemical and functional properties. This has resulted in the search of these excipients from different sources and modifications of existing ones. ${ }^{1,2}$ Moreover, attention is being shifted to excipients from natural sources. They are generally regarded as being biodegradable, biocompatible, environmental friendly and relatively inexpensive. ${ }^{2,3}$

Starch, a polysaccharide comprising of two types of glycan; amylose and amylopectin is one of the most commonly used excipients in pharmaceutical industries. Apart from its wide range of applications in different industries, native and modified starches

Correspondence to: Chukwuemeka P. Azubuike E-mail: cazubuike@unilag.edu.ng; Tel.: +234-8033618556

Dhaka Univ. J. Pharm. Sci. 18(1): 21-29, 2019 (June) DOI: https://doi.org/10.3329/dujps.v18i1.41423 are employed as disintegrants, fillers, binders, glidants, coating and dusting media in solid dosage formulations as well as carriers in controlled release formulations. ${ }^{1,4}$ Starch is the most abundant carbohydrate reserve in plants and it is present in leaves, flowers, fruits, seeds, different types of stems and roots. The accumulation pattern of starch granules in each plant tissue, shape, size, structure and composition is unique to each botanical species. ${ }^{5}$ The methods employed in the isolation of starch from other plant components also affect its properties; hence the physicochemical properties of starches obtained from different sources and also using different extraction/modification techniques are expected to indicate different physicochemical and functional properties.

Native starch is starch isolated from its botanical source with minimal treatment. It has limited 
industrial applications due to certain undesirable physicochemical properties. Some of these undesirable properties could be overcome by modification of the native starch. ${ }^{6,7}$ One of the chemical methods of starch modification is phosphorylation. Phosphorylation of starch involves chemical substitution of the free hydroxyl groups of anhydroglucose units of starch molecule with phosphate via an esterification process. ${ }^{8}$ Studies have shown that a phosphate group in starch prevents crystallization, increases hydration capacity and affects the viscosity of the final product. ${ }^{9}$ It also has reported to give clear pastes of high consistency, with good emulsifying and freeze-thaw stability. ${ }^{10}$ One of these sources of native starch is a crop named tiger nut (Cyperus esculentus)

C. esculentus is an annual or perennial herb that produces rhizomes and small spherical nuts belongs to both temperate and tropic regions of the world. ${ }^{2}$ Although, in many parts of the world where it is found, it is a common weed but some varieties are cultivated and readily available in the market. $C$. esculentus has a high yield per acre of cultivation, great oil content useful for cooking and soap production, and also quality starch content. ${ }^{11,12}$ The tubers are edible and have many uses in Ayuverdic medicine. $^{2}$

Some studies have reported the properties and potentials of native starch isolated from $C$. esculentus. $^{2,4,12}$ Tiger nut starch has been modified by forced retrogradation of the acidic gel by freezing and thawing process and employed as an excipient for direct compression. ${ }^{13}$ However, to the best of our knowledge, the physicochemical properties of phosphorylated tiger nut starch have not been studied. Since the physicochemical properties of starches obtained from different botanical sources differs ${ }^{14}$, this study was aimed at characterization of phosphorylated tiger nut starch and evaluation of its disintegrant property in immediate release ibuprofen tablet formulation.

Ibuprofen, an analgesic,belongs to the biopharmaceutical classification system (BCS) Class II drug characterised by low solubility and high permeability. Ibuprofen $\left(\mathrm{C}_{13} \mathrm{H}_{18} \mathrm{O}_{2}\right)$ shows bad dissolution and tableting behaviour due to its hydrophobic structure. It has a high tendency of sticking to the punches. ${ }^{15}$ Additionally it is highly cohesive and this results in poor flow hence there is need for it to be formulated with excipients that will enhance its flowability, compression behaviour, shorten its disintegration time and generally improve its dissolution.

\section{MATERIALS AND METHODS}

Materials. C. esculentus tubers (tiger nuts) were authenticated by Mr. O Oyebanji of the Department of Botany, University of Lagos, Nigeria with the voucher specimen number LUH 7591. Ibuprofen powder, sodium starch glycolate, lactose, gelatin, talc and magnesium stearate were gift from Phamatex Industry Limited, Lagos, Nigeria. All other reagents used in the study were of analytical grade and were used without further purification.

Isolation of Tiger nut starch. Tiger nut starch (TNS) was isolated according to method employed by Manek with some modifications. ${ }^{4}$ The tiger nuts were rinsed with distilled water and dried in a hot air oven (B \& $\mathrm{T}$, England) set at $50^{\circ} \mathrm{C}$ for $3 \mathrm{hrs}$. The dried nuts $(3 \mathrm{~kg})$ were pulverized $(>1 \mathrm{~mm})$, treated with several portions of absolute ethanol and then dried in the hot air oven $\left(50^{\circ} \mathrm{C}\right)$ for $2 \mathrm{hrs}$. Thereafter, they were soaked in 12 litres of the sodium metabisulphite solution $(0.075 \%$, w/v) for $16 \mathrm{hrs}$ and were filtered through a muslin cloth of $150 \mu \mathrm{m}$ pore. The starch suspension was allowed to stand for $18 \mathrm{hrs}$ before the supernatant was decanted and washed repeatedly with distilled water. The resulting starch cake was dried for $5 \mathrm{hrs}$ at $50^{\circ} \mathrm{C}$, pulverized and passed through a $250 \mu \mathrm{m}$ mesh.

Preparation of Tiger nut phosphorylated starch. Tiger nut phosphorylated starch (TNP) was prepared according to a previous method of Sung with some modifications. ${ }^{16}$ TNS $(50 \mathrm{~g})$ and anhydrous di-sodium hydrogen orthophosphate ( $15 \mathrm{~g})$ was suspended in $50 \mathrm{ml}$ of water and stirred continuously for $20 \mathrm{~min}$. The slurry was then filtered and conditioned for $12 \mathrm{hrs}$ at $28^{\circ} \mathrm{C}$. To enhance 
phosphorylation, the mixture was then heated at $130^{\circ} \mathrm{C}$ for $3 \mathrm{~h}$. The product obtained was pulverized, screened through a $250 \mu \mathrm{m}$ mesh and stored in a dry airtight container.

Characterization of the starches. The physicochemical and micrometric properties of the native and modified starches were evaluated.

Powder flow characteristics. The flow properties of the native tiger nut starch (TNS), phosphorylated tiger nut starch (TNP) and a commercial disintegrant, sodium starch glycolate (SSG) were studied by measurement of angle of repose, bulk and tapped densities. There parameters were evaluated using methods employed in an earlier study. ${ }^{17}$ The Carr's compressibility index (CI) and Hausner's ratio (HR) were determined by computing the data generated from bulk and tapped densities using Eqs 1 and 2.

$$
\text { Carr's compressibility index }=100 \mathrm{x} \frac{\text { tapped density }- \text { bulk density }}{\text { tapped density }}
$$

$$
\text { Hauner's ratio }=\frac{\text { tapped density }}{\text { tapped density }}
$$

Hydration and Swelling capacities. Hydration capacity data of the starches were obtained by weighing $1 \mathrm{~g}$ of each sample of starch powder and pouring into centrifuge tubes. Ten millilitres of distilled water was added and mixed for $2 \mathrm{~min}$. The mixture was then centrifuged for $10 \mathrm{~min}$ at $100 \mathrm{rpm}$. The supernatant obtained was decanted and the sediment weighed. The hydration capacity was calculated as the ratio of sediment weight to the dry sample weight.

For determination of swelling capacity (S), $2 \mathrm{~g}$ of each test powder was added each to $10 \mathrm{ml}$ of water and light liquid paraffin taken in two different graduated test tubes and mixed. The dispersion in the tubes was allowed to stand for $12 \mathrm{~h}$. The volumes of the sediment in water (V2) and liquid paraffin (VI) were recorded. ${ }^{18}$ The swelling index of each powder was calculated as stated in Eq 3.

$$
\mathrm{S}=\frac{(\mathrm{V} 2-\mathrm{V} 1)}{\mathrm{V} 1} \times 100 \%
$$

Fourier transform infrared spectroscopy (FTIR). FTIR spectra of the TNS, TNP, SCG and ibuprofen powder, were obtained. Five milligrams each of the starches were diluted with potassium bromide $\mathrm{KBr}(50 \mathrm{mg})$ before acquisition and the background value from pure potassium bromide was determined before the sample was scanned. The spectra were recorded in transmission mode from 4,000 to $500 \mathrm{~cm}^{-1}$ under dry air in a FTIR spectrometer (Bruker, South Africa). For compatibility study, FTIR spectra of 1:1 mixture of ibuprofen and TNP as well as that ibuprofen and TNP were obtained.

Scanning electron microscopy (SEM). The starch powders were mixed with ethanol to obtain a $1 \%$ suspension. The suspensions were evenly smeared on SEM specimen stubs with double sided adhesive tape and were coated with gold powder. The micrographs were obtained with an accelerating potential of $30 \mathrm{kV}$ under low vacuum using SEM (Pro X, Netherlands).

Preparation of ibuprofen tablets. Eight batches of tablets containing $200 \mathrm{mg}$ of ibuprofen were formulated using wet granulation method (Table 1). Four batches contained TNP at concentrations of 5.0, $7.5, \quad 10.0$ and $15.0 \% \mathrm{w} / \mathrm{w}$ as disintegrants, respectively while other four batches contained SCG at similar concentrations. The disintegrants were added intra-granularly. The granules were compressed into round tablets using a multi punch tableting machine (Manesty, Liverpool) at the same compression settings. The ibuprofen tablets produced 
were stored in an airtight, amber coloured bottles for $24 \mathrm{~h}$ prior to evaluation of the tablets properties.

Evaluation of tablets. Randomly selected tablets from each batch were evaluated for thickness, uniformity of weight, crushing strength and friability using methods reported in a previous study. ${ }^{19}$

Disintegration time and dissolution profiles. The disintegration times of the ibuprofen tablets were determined in distilled water using Copley Tablet disintegration tester at $37.0 \pm 0.5^{\circ} \mathrm{C}$. The time taken for the tablets to disintegrate and pass through disintegration tester mesh was recorded.

Dissolution profiles of the different batches of the ibuprofen tablets were determined using dissolution apparatus (RC-1, China) in $0.1 \mathrm{~N} \mathrm{HCl}$ according to method detailed in British Pharmacopoeia. ${ }^{20}$ Samples of the dissolution medium $(5 \mathrm{ml})$ were withdrawn and filtered through a millipore filter of $0.45 \mu \mathrm{m}$ mesh size at specified time interval of $0,5,10,15,20,25$ and $30 \mathrm{~min}$. respectively. The absorbance was measured at a wavelength of $243 \mathrm{~nm}$ and the concentration calculated.

Data analysis. The data emanating from the study was analyzed using statistical package for social sciences version 20.0 (SPSS Inc., Chicago, IL, USA). The results were presented in tables and graphs and comparison was made with the standard using the student's t-test and analyses of variance. where $\mathrm{p}$ value $<0.05$ was considered as statistically significant.

\section{RESULTS AND DISCUSSION}

The process of tiger nut starch modification by phosphorylation of free hydroxyl groups of anhydroglucose units involved the destruction of the semicrystalline starch granules and the effective dispersion of the component polymers. ${ }^{21}$ Hence, changes in the physicochemical properties are expected.

Powder flow characteristics: Angle of repose, Carr's compressibility index (CI) and Hausner ratio (HR) are indices used to evaluate the flow properties of powder. Their values for the starches are presented in table 2. CI and HR are based on the values of the tapped and bulk density. CI values of 16-20 and 2125 are considered to have fair and passable flow character, respectively below 15 represent good flow while HR values of 1.19-1.25 and 1.26-1.34 are considered to have fair and passable flow character. ${ }^{22}$ There was a significant difference in the values of CI and HR for the TNS and TNP. The CI and HR values obtained for the samples indicated that TNP had good flow property while TNS had a fair flow. Moreover, the flow property of TNP was slightly better than that of SSG. The data obtained for angles of repose of the powders (Table 1) correlated well with the results of $\mathrm{CI}$ and HR indices.

Table 1. Percentage (w/w) composition of ibuprofen tablets containing different concentrations of the starches as disintegrant.

\begin{tabular}{lcccccccc}
\hline Ingredients & FSSG5 & FSSG7.5 & FSSG10 & FSSG10 & FTNP5 & FTNP7.5 & FTNP10 & FTNP15 \\
\hline Ibuprofen & 200 & 200 & 200 & 200 & 200 & 200 & 200 & 200 \\
Gelatin & 2.5 & 10 & 10 & 10 & 10 & 10 & 10 & 10 \\
SSG & 5 & 7.5 & 10 & 15 & - & - & - & - \\
TNP & - & - & - & - & 5 & 7.5 & 10 & 15 \\
Magnesium stearate & 1.5 & 1.5 & 1.5 & 1.5 & 1.5 & 1.5 & 1.5 & 1.5 \\
Talc & 1 & 1 & 1 & 1 & 1 & 1 & 1 & 1 \\
Lactose & 100 & 100 & 100 & 100 & 100 & 100 & 100 & 100 \\
\hline
\end{tabular}

Formulations FSSG5, FSSG7.5, FSSG10 and FSSG15 contain 5.0, 7.5, 10.0 and 15.0\% w/w sodium glycolate as disintegrant respectively while FTNP5, FTNP7.5, FTNP10 and FTNP15 contaRasenack, N. and Muller, B.W (2002) Ibuprofen crystals with optimized properties. Int. J. Pharm. Sci. 245(1-2): 9-24. in 5.0, 7.5, 10.0 and 15.0\% w/w tiger nut phosphate starch. 
Hydration and swelling capacities. Hydration capacity affects the functional properties of starch especially its ability to imbibe water and swell. The data obtained for hydration capacity was in decreasing order of TNP> SSG>TNS (Table 2). The hydration capacity of TNS was increasedon phosphorylation.

Swelling is one of the mechanisms of disintegration and is a critical property for material with potential as disintegrant and intended for formulating immediate release solid dosage formulations. ${ }^{23}$ The data for swelling index was in the order TNP> SSG> TNS. Increase in swelling index of both TNP and SSG over native starch could enhance their disintegrating activity in the tablet as it could lead to the absorption of large quantities of water into the tablet mass and the subsequent generation of a higher swelling force. ${ }^{24}$ This would initiate the active mechanism of disintegration at a faster rate than for natural starch disintegrants.

Fourier transform infrared spectroscopy: The FTIR spectra of the starches are characteristic of granular starches although phosphorylation caused minor shift in peak/band positions/intensities (Figure 1). The FT-IR spectra of the starches show a characteristic peak at $3281.8 \mathrm{~cm}^{-1}$ due to $\mathrm{O}-\mathrm{H}$ stretching vibration. The $-\mathrm{CH}_{2}$ symmetrical band is found at $1342 \mathrm{~cm}^{-1}$. Weak absorption at $1641.9 \mathrm{~cm}^{-1}$ for the TNS probably features the tightly bound water molecules present in TNS molecules. The absorption bands in the range of $1342-1005.5 \mathrm{~cm}^{-1}$ are characteristics of $\mathrm{C}-\mathrm{O}$ stretching in $\mathrm{C}-\mathrm{O}-\mathrm{C}$ and $\mathrm{C}-$ $\mathrm{O}-\mathrm{H}$ in the glycosidic molecule. A more detailed description of FTIR spectrum of starch molecule has been reported in literature. ${ }^{25}$ The intensity of the absorption band of $\mathrm{O}-\mathrm{H}$ stretching for TNP was reduced and also shifted to $3134.7 \mathrm{~cm}^{-1}$. This could be due to the interaction of $\mathrm{O}-\mathrm{H}$ group with the phosphate group. The reduction in intensity of this band might also correspond to partly substituted $\mathrm{O}-\mathrm{H}$ group with phosphate group during the reaction. The $-\mathrm{CH}_{2}$ symmetrical band for TNP shifted to 1258.4 $\mathrm{cm}^{-1}$ as a result of the modification.

Table 2. Physicochemical properties of the starche samples $( \pm S D, n=3)$.

\begin{tabular}{lccc}
\hline Parameters & TNS & TNP & SSG \\
\hline Bulk density $(\mathrm{g} / \mathrm{ml})$ & $0.65 \pm 0.10$ & $0.71 \pm 0.04$ & $0.73 \pm 0.02$ \\
Tapped density $(\mathrm{g} / \mathrm{ml})$ & $1.07 \pm 0.01$ & $0.84 \pm 0.03$ & $0.86 \pm 0.02$ \\
Hausner's ratio & $1.64 \pm 0.20$ & $1.16 \pm 0.16$ & $1.19 \pm 0.07$ \\
Carr's index $(\%)$ & $39.12 \pm 0.07$ & $14.3 \pm 0.6$ & $16.4 \pm 0.7$ \\
Angle of repose $(\theta)$ & $43.6 \pm 0.9$ & $33.5 \pm 0.5$ & $32.9 \pm 0.2$ \\
Swelling capacity $(\%)$ & $53.2 \pm 3.0$ & $400.0 \pm 5.1$ & $260.1 \pm 3.0$ \\
Hydration capacity & $8.6 \pm 0.3$ & $12.7 \pm 0.24$ & $9.0 \pm 0.3$ \\
\hline
\end{tabular}

TNS=Tiger nut starch; TNP=Tiger nut phosphate; $\mathrm{SSG}=$ Sodium starch glycolate

To study the compatibility of TNP and ibuprofen powder, FTIR spectrum of an equal mixture of the two powders was recorded (Figure 2). The characteristic peak of high intensity for ibuprofen in the regions between $1703-1709 \mathrm{~cm}^{-1}$ due to carbonyl stretching $(\mathrm{C}=\mathrm{O})$ was maintained with addition of TNP thus indicating no interaction. Similar result was obtained for SSG samples. From the FTIR spectra in Figure 2, it can be concluded that TNP and SSG powders are compatible with ibuprofen as they caused an insignificant shift in wave numbers of some functional groups and intensities of the bands.

Scanning electron microscopy (SEM): SEM study of the particle morphology (Figure 3) showed that TNS appeared round or oval in shape and they occurred singly with few clusters while TNP 
appeared smooth, disc-like, irregularly shaped and in clusters with some void spaces.

Tablet properties: The results of properties of the prepared eight batches of ibuprofen tablets are presented in table 3. There was no statistical difference in the thicknesses of the tablets for all the batches. The mean weight of the tablet produced ranged from 389.2 to $405.2 \mathrm{mg}$ and the percentage deviation of all the batches were within standard specifications. For weight uniformity, acceptable limit of deviation for tablets weighing more than 250 $\mathrm{mg}$ is minimum of 18 tablets with $5 \%$ deviation and maximum of 2 tablets with $109 \%$ deviation. ${ }^{22}$ As shown in table 3 all the tablets formulated have friability values within limits specified by the British Pharmacopoeia, $(<0.8 \%)$. This shows the ability of the tablets to withstand abrasion. ${ }^{20}$ The crushing strength of the tablets fall between 9.5 to $10.5 \mathrm{~kg} / \mathrm{cm}^{2}$ and are within acceptable range.

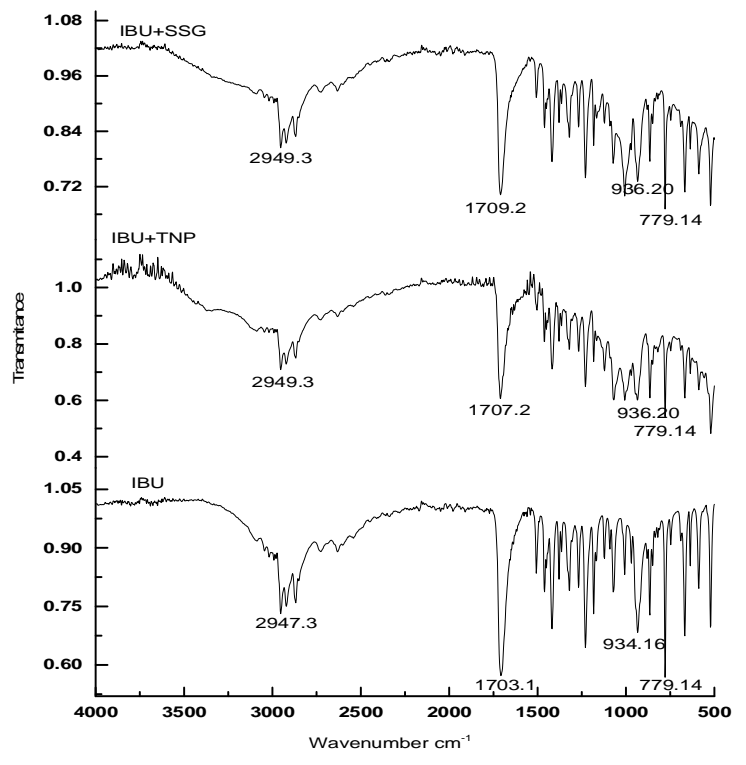

Figure 2. Stacked plots of FTIR spectra of ibuprofen (IBU), mixture of IBU and TNP, mixture of IBU and SSG.

Figure 1. Stacked plot of FTIR spectra of TNP, TNS, SSG.

Table 3. Properties of the ibuprofen tablets $( \pm$ SD).

\begin{tabular}{|c|c|c|c|c|c|c|c|c|}
\hline Parameters & FSSG5 & FSSG7.5 & FSSG10 & FSSG15 & FTNP5 & FTNP7.5 & FTNP10 & FTNP15 \\
\hline $\begin{array}{l}\text { Thickness (mm) } \\
(\mathrm{n}=10)\end{array}$ & $5.3 \pm 0.1$ & $5.4 \pm 0.9$ & $5.3 \pm 0.4$ & $5.3 \pm 1.2$ & $5.4 \pm 0.6$ & $5.3 \pm 0.7$ & $5.4 \pm 0.9$ & $5.5 \pm 0.8$ \\
\hline $\begin{array}{l}\text { Uniformity of } \\
\text { weight }(\mathrm{mg}) \\
(\mathrm{n}=20)\end{array}$ & 402.5 & 395.6 & 405.2 & 389.2 & 393.1 & 396.1 & 401.6 & 395.3 \\
\hline $\begin{array}{l}\% \text { deviation on } \\
\text { weight }\end{array}$ & 1.2 & 1.9 & 1.5 & 2.1 & 1.8 & 0.6 & 1.2 & 1.7 \\
\hline $\begin{array}{l}\text { Friability test } \\
(\%)(\mathrm{n}=10)\end{array}$ & 0.39 & 0.42 & 0.37 & 0.42 & 0.34 & 0.46 & 0.49 & 0.62 \\
\hline $\begin{array}{l}\text { Crushing strength } \\
\left(\mathrm{kg} / \mathrm{cm}^{2}\right)(\mathrm{n}=10)\end{array}$ & $10.5 \pm 1$ & $9.7 \pm 0.8$ & $10.0 \pm 0.6$ & $9.9 \pm 0.4$ & $10.0 \pm 0.5$ & $9.6 \pm 0.1$ & $9.5 \pm 0.3$ & $9.7 \pm 0.3$ \\
\hline $\begin{array}{l}\text { Disintegration } \\
\text { Time }(\min )(n=6)\end{array}$ & $14.21 \pm 0.20$ & $12.00 \pm 0.24$ & $11.27 \pm 0.40$ & $8.23 \pm 0.10$ & $15.23 \pm 0.12$ & $11.23 \pm 0.20$ & $10.00 \pm 0.34$ & $8.15 \pm 0.16$ \\
\hline $\begin{array}{l}\text { Disintegration } \\
\text { Efficiency (DER) }\end{array}$ & 1.89 & 1.92 & 2.40 & 2.86 & 1.93 & 1.86 & 1.94 & 1.92 \\
\hline DERc & - & - & - & - & 1.02 & 0.97 & 1.01 & 0.80 \\
\hline
\end{tabular}

Formulations FSSG5,FSSG7.5, FSSG10 and FSSG15 contain 5.0 7.5, 10.0 and 15.0\% w/w sodium glycolate as disintegrant respectively while FTNP5, FTNP7.5, FTNP10 and FTNP15 contain5.0, 7.5, 10.0 and 15.0\% w/w tiger nut phosphate starch. DERc is dimensionless disintegrant quantity 

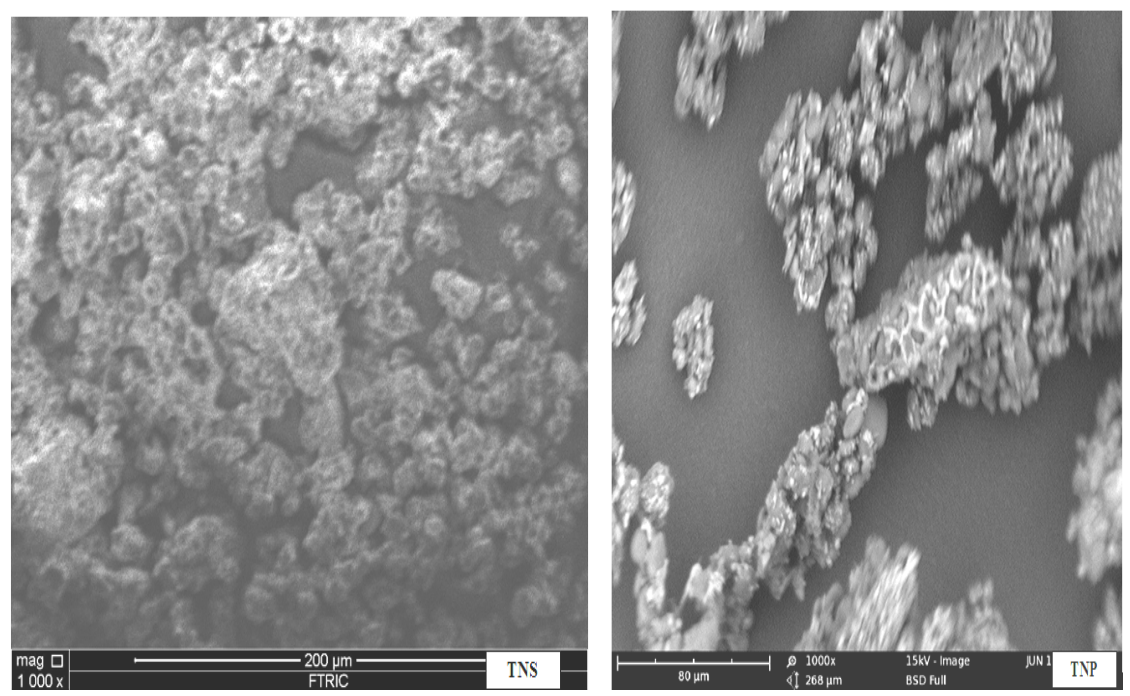

Figure 3. Scanning electron micrographs of a. Tiger nut native starch and b. Tiger nut phosphate starch at magnification of 1000.
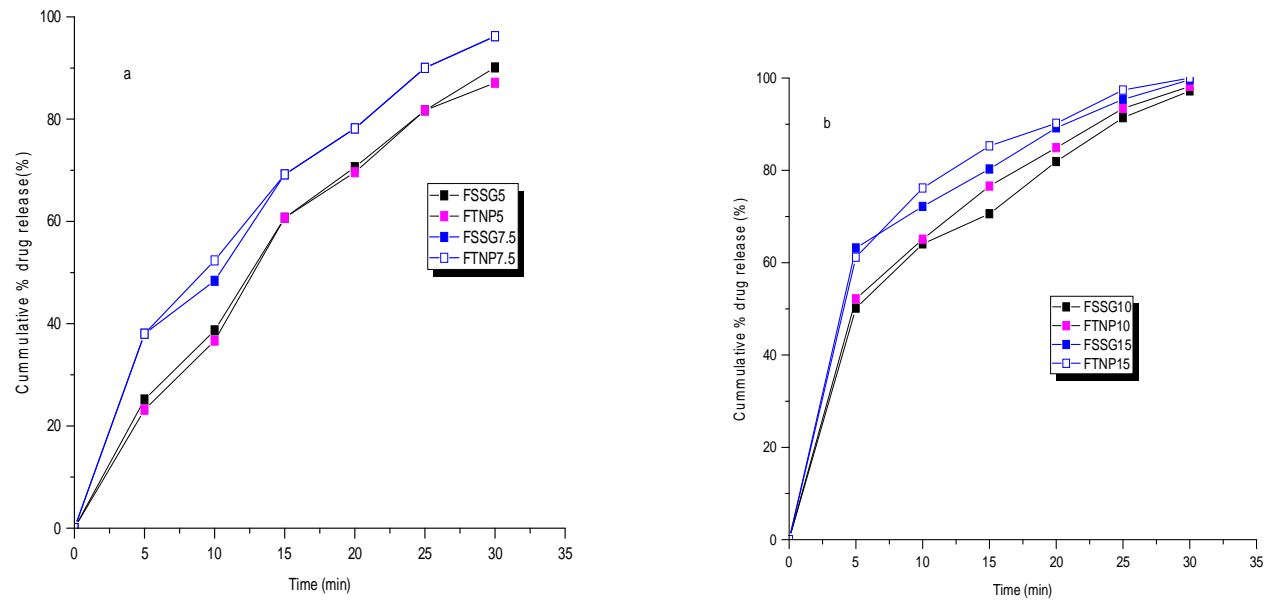

Figure 4. Dissolution profiles of ibuprofen tablets containing a. 5.0 and 7.5\% SSG and TNP as disintegrants and b. 10.0 and $15.0 \%$ SSG and TNP as disintegrants.

Disintegration time and dissolution profiles. The disintegration times for all the batches of the tablets were within $15 \mathrm{~min}$ of the BP limit of disintegration time for uncoated tablets. ${ }^{20} \mathrm{TNP}$ at concentrations of 7.5, 10.0, and $15.0 \%$ had comparable disintegration times with the same concentrations of SSG. There was a decrease in disintegration time with increase in concentration of the two disintegrants. This observation is in consistence with the report of previous study. ${ }^{26}$ To compare the disintegration efficiency of TNP and SSG, the data obtained from disintegration efficiency ratio, DER (which is a measure of the balance between mechanical and disintegrant property of tablets) and dimensionless disintegration quantity (DERc), (which is a measure that compares the efficiency of the two tablet disintegrants) were used. ${ }^{27} \mathrm{~A}$ value of DERc more than 1 indicates that the DER of the experimental starch is better than that of the standard disintegrant. ${ }^{27}$ From table 3, DERc values of different concentrations of TNP where at threshold of 1.0, hence it can be concluded that TNP and SSG have similar disintegration property. 
The dissolution profiles of the eight formulations are illustrated in figure 4. All the batches of passed pharmacopoeial dissolution test limit (80\% of drug released in 30 minutes). Visually, it appears that there are no considerable differences between them. Applying two fit factors [difference factor $(f l)$ and similarity factor $(f 2)]$ that compare the dissolution profiles of a pair of drug products differences/ similarities in the dissolution profiles might be established. ${ }^{28}$ According to Food and Drug Administration (FDA $)^{29}$ guides for industry, two dissolution profiles are considered similar and bioequivalent, if the value of $f 1$ is between 0 and 15 and the value of $f 2$ is between 50 and 100 . The value of $f 1$ is 0 when the mean dissolution profiles are identical and increases proportionally as the difference between the mean dissolution profiles increases whereas $f 2$ is 100 when the profiles are identical. From the calculated $f 2$ values from dissolution profiles (Figure 4), at the same concentration for TNP and SSG, the $f 2$ values are greater than 75 , clearly establishing similarity and tablets formulated with the two disintegrants are interchangeable. These results imply that tiger nut starch phosphate may provide similar disintegrant efficiency without compromising drug release properties.

\section{CONCLUSION}

Phosphorylation of native tiger nut starc hled to improve flow properties as well as swelling and hydration capacities compared to the native starch. The physicochemical and disintegrant properties of the tiger nut starch phosphate were comparable to the commercial brand disintegrant, sodium starch glycolate. FTIR study confirmed modification and also showed that TNP is compatible with ibuprofen powder as there was no evident interaction between TNP and ibuprofen. Phosphorylation of native tiger nut starch obtained from the tubers of $C$. esculentus yielded starch phosphate with a promising disintegrant potential comparable to sodium glycolate in tablet formulations.

\section{REFERENCES}

1. Mohapatra, S., Siddiqui, A.A., Anwar, M., Bhardwaj, N., Akhter, S. and Ahmad, F.J. 2018. Synthesis and characterization of novel carboxymethyl Assam Bora rice starch for the controlled release of cationic anticancer drug based on electrostatic interactions. AAPS Pharm. Sci. Tech. 19, 134-147.

2. Agboola, B.S., Ajala, T.O. and Odeku, O.A. 2018. The glidant properties of Cyperus esculentus, L (Tigernut) starch in metronidazole tablet formulation. Starch Stärke. 70, 1700047.

3. Su, X., Xiao, C. and Hu, C. 2018. Facile preparation and dual responsive behaviours of starch-based hydrogel containing azo and carboxylic groups. Inte. J. Biol. Macromol. 115,1189-1193.

4. Manek, R.V., Builders, P.F., Kolling, W.M., Emeje, M. and Kunle, O.O. 2012. Physicochemical and binder properties of starch obtained from Cyperus esculentus.AAPS Pharmscitech. 13, 379-388.

5. Smith, A.M. 2001. The biosynthesis of starch granules. Biomacromol. 2, 335-341.

6. Yadav, B.S., Guleria, P. and Yadav, R.B. 2013. Hydrothermal modification of Indian water chestnut starch: Influence of heat-moisture treatment and annealing on the physicochemical, gelatinization and pasting characteristics. LWT-Food Science and Technol. 53, 211-217.

7. Ashogbon, A.O. and Akintayo, E.T. 2014. Recent trend in the physical and chemical modification of starches from different botanical sources: A review. Starch $\square$ Stärke. 66, 4157.

8. Sung, J.H., Park, D.P., Park, B.J., Choi, H.J. and Jhon, M.S. 2005. Phosphorylation of potato starch and its electrorheological suspension. Biomacromolecules. 6, 21822188 .

9. Viksø-Nielsen, A., Blennow, A., Jørgensen, K., Kristensen, K.H., Jensen, A. and Møller, B.L. 2001. Structural, physicochemical, and pasting properties of starches from potato plants with repressed r 1-gene. Biomacromolecules 2 , 836-843.

10. Sitohy, M.Z., Labib, S.M., El-Saadany, S.S. and Ramadan, M.F. 2000. Optimising the conditions for starch dry phosphorylation with sodium mono- and dihydrogen orthophosphate under heat and vacuum. Starch Stärke 52, 95-100.

11. Belewu, M.A. and Abodunrin, O.A. 2008. Preparation of Kunnu from unexploited Rich Food Source: Tiger nut (Cyperus esculentus). Pakistan J. Nutr.7, 109-111.

12. Builders, P.F., Mbah, C.C., Adama, K.K. and Audu, M.M. 2014. Effect of $\mathrm{pH}$ on the physicochemical and binder properties of tigernut starch. Starch Stärke. 66, 281-293. 
13. Builders, P.F., Anwunobi, P.A., Mbah, C.C. and Adikwu, M.U. 2013. New direct compression excipient from tigernut starch: physicochemical and functional properties. AAPS Pharm. Sci. Tech. 14, 818-827.

14. Zhang, D., Mu, T. and Sun, H. 2018. Effects of starch from five different botanical sources on the rheological and structural properties of starch-gluten model doughs. Food Res. Inte. 103, 156-162.

15. Rasenack, N. and Muller, B.W. 2002. Ibuprofen crystals with optimized properties. Int. J. Pharm. Sci. 245, 9-24.

16. Sung, J.H., Park, D.P., Park, B.J., Choi, H.J. and Jhon, M.S. 2005. Phosphorylation of potato starch and its electrorheological suspension. Biomacromolecules 6, 21822188

17. Azubuike, C.P. and Aloko, S. 2017. Preliminary studies on binding potentials of defatted cake derived from Blighia sapida seeds in ascorbic acid tablets. J. Reports Pharm. Sci. 6,167-179

18. Chowdary, K.P.R. and Enturi, V. 2011. Preparation, characterization and evaluation of starch phosphate: A new modified starch as directly compressible vehicle in tablet formulations. J. Pharmacy Res. 4, 3241-3243.

19. Azubuike, C.P. and Oluyase, S.O. 2014. Physicochemical and bioequivalence studies on some brands of levofloxacin tablets registered in Nigeria. British J. Pharm. Res. 4, 19761987.

20. British Pharmacopoeia Commission 2017. stationary office medicines and healthcare products regulatory agency London, TSO (The Stationery Office), UK.

21. Rajan, A., Sudha, J.D. and Abraham, T.E. 2008. Enzymatic modification of cassava starch by fungal lipase. Indus. Crops Prod. 27, 50-59.
22. United States Pharmacopoeia. United States Pharmacopoeia National Formulary (USP 41 NF 36). 2018. Rockville, Md: United States Pharmacopoeia Convention, Inc.

23. Ferrari, F., Bertoni, M., Bonferoni, M.C., Rossi, S., Caramella, C. and Nyström, C. 1996. Investigation on binding and disintegration properties of pharmaceutical materials. Inte. J. Pharm. 136, 71-79.

24. Guyot-Hermann, A.M., 1992. Tablet disintegration and disintegrating agents. STP Pharma Sci. 2, 445-462.

25. Fang, J.M., Fowler, P.A., Tomkinson, J. and Hill, C.A.S. 2002. The preparation and characterisation of a series of chemically modified potato starches. Carbohydr. Poly. 47, 245-252.

26. Odeku, O.A. and Akinwande, B.L., 2012. Effect of the mode of incorporation on the disintegrant properties of acid modified water and white yam starches. Saudi Pharm. J. 20, 171-175.

27. Pachuau, L., Dutta, R.S., Roy, P.K., Kalita, P. and Lalhlenmawia, H. 2017. Physicochemical and disintegrant properties of glutinous rice starch of Mizoram, India. Int. J. Biol. Macromol. 95, 1298-1304.

28. Moore, J.W. 1996. Mathematical comparison of dissolution profiles. Pharm. Technol. 20, 64-75.

29. FDA/CDER (Food and Drug Administration, Center for Drug Evaluation and Research) 2000. Waiver of in vivo bioavailability and bioequivalence studies for immediaterelease solid oral dosage forms based on a biopharmaceutics classification system; guidance for industry; U.S. Department of Health and Human Services, Food and Drug Administration (FDA), Center for Drug Evaluation and Research (CDER), U.S. Government Printing Office: Washington, DC. 